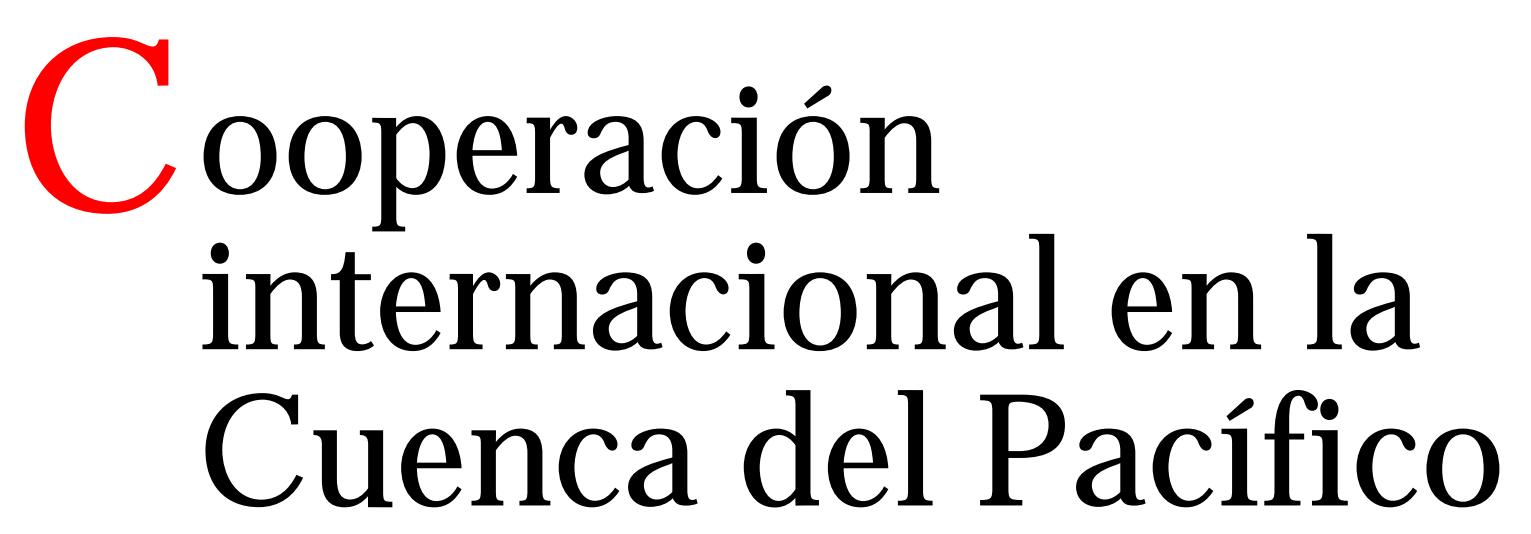

\title{
La protección de los derechos de propiedad intelectual en la ASEAN•
}

\section{I} ntroducción

La protección de los derechos de propiedad intelectual en la ASEAN empieza a ser tomada formalmente en cuenta a partir de la promulgación del Acuerdo Marco para la Cooperación sobre Propiedad Intelectual en la ASEAN. Dicho acuerdo se firmó el 15 de diciembre de 1995, en Bangkok, Tailandia. Sin embargo, la entrada en vigor se especificó que fuera de acuerdo con la decisión de cada país de establecer el momento apropiado para su aceptación. Así, algunos optaron por la entrada casi inmediata (por ejemplo Singapur y Tailandia, los cuales depositaron el instrumento de aceptación el 28 y 29 de diciembre de ese mismo año, respectivamente), mientras que otros la pospusieron por unos años (es el caso de Brunei, que aceptó su entrada en vigor a partir del 5 de junio de 1999; en tanto que Malaisia, hasta la fecha, no ha depositado su instrumento de aceptación).

En el acuerdo mencionado se reconoce la importancia de los derechos de propiedad intelectual en la conducción del comercio y los flujos de inversión entre los estados miembros de la ASEAN, y la relevancia de la cooperación

* Investigador del Departamento de Estudios del Pacífico, de la Universidad de Guadalajara.

ORCID http://orcid.org/0000-0003-0344-6895 sobre la materia en la región. Por esta razón, el acuerdo propone fomentar una cooperación más estrecha y un mayor entendimiento entre los países de la región en el campo de la propiedad intelectual y aspectos relacionados, con el fin de proveer una base firme para el progreso económico, la realización del área de libre comercio de la ASEAN y la prosperidad entre sus estados miembros. ${ }^{1}$

En el presente trabajo se hará referencia a las principales disposiciones de la ASEAN en materia de protección de los derechos de propiedad intelectual. Se estudiarán los elementos que muestran la importancia que otorga la ASEAN a la protección de los derechos mencionados. Se analizará el Acuerdo Marco para la Cooperación sobre Propiedad Intelectual en la ASEAN, con el fin de ir rescatando los principales aspectos sobre la materia de interés para llevar a cabo el presente trabajo. De esta manera, se examinará hasta qué grado se ha puesto en operación el régimen internacio$\mathrm{nal}^{2}$ representado a nivel global por el Acuerdo sobre los Aspectos de los Derechos de Propiedad Intelectual Relacionados con el Comercio ADPIC y su influencia en la determinación del nivel de protección de los derechos de propiedad intelectual en la ASEAN. 
Propiedad intelectual en la ASEAN y el ADPIC

El Acuerdo Marco para la Cooperación sobre Propiedad Intelectual en la ASEAN establece que los estados miembros deben poner en práctica arreglos al interior de la asociación de modo que éstos se vinculen con los objetivos, principios y normas asentadas en los convenios relevantes en la materia y el ADPIC. ${ }^{3,4}$ Es decir, no obliga formalmente a la adopción del ADPIC, sino que recomienda la adopción de medidas que cumplan con sus obligaciones en el marco de éste y otros convenios internacionales. Debemos tomar en cuenta que de los diez países que conforman la asociación actualmente, tres de ellos no son miembros de la omc, ${ }^{5}$ por lo que la adopción del ADPIC no es obligatoria, ni en el marco de la misma omc ni, mucho menos, bajo las disposiciones de la ASEAN.

Además, entre los objetivos del acuerdo no aparece ningún aspecto que haga referencia a algún mecanismo para la puesta en operación de medidas efectivas que protejan los derechos de propiedad intelectual en el área. Los objetivos establecidos en el acuerdo sólo mencionan que los estados miembros deberán fortalecer la cooperación en el campo de la propiedad intelectual por medio de una actitud abierta y orientada al exterior, con vistas a contribuir en la promoción y el crecimiento de la liberalización del comercio regional y global. También contempla que se debe promover la cooperación en el campo de la propiedad intelectual entre las agencias gubernamentales, así como entre los sectores privados y cuerpos profesionales de la ASEAN.

El acuerdo considera que se deberá explorar la posibilidad de establecer convenios de cooperación al interior de la asociación en el campo de la propiedad intelectual, con el fin de contribuir a la ampliación de la solidaridad en ésta, a la promoción de la innovación tecnológica y a la transferencia y diseminación de tecnología. ${ }^{6}$

Entre los objetivos más concretos del acuerdo están los de explorar la posibilidad de establecer tanto un sistema de patentes como de marcas comerciales, para promover la protección de las patentes y las marcas comerciales en toda la región, teniendo en mente los desarrollos regionales e internacionales. Además, contempla que los estados miembros deberán realizar consultas sobre el desarrollo de sus sistemas de protección de derechos de propiedad intelectual, con la intención de crear prácticas y estándares de protección de tales derechos que sean consistentes con los internacionales. ${ }^{7}$ Sin embargo, dicho acuerdo no menciona nada especial para la protección de los derechos de autor, uno de los aspectos de mayor importancia entre los campos de la propiedad intelectual.

Los principios establecidos en el acuerdo consideran que los estados miembros de la asociación deberán cumplir con los "beneficios mutuos" en la puesta en práctica de las medidas o iniciativas enfocadas a ampliar la cooperación sobre propiedad intelectual en la ASEAN. Pero advierte que se debe tener cuidado y considerar los convenios internacionales sobre protección de los derechos de propiedad intelectual de los que sean miembros y de las obligaciones asumidas bajo las disposiciones del ADPIC.

Esto indica que puede haber cierta contradicción entre los principios fundamentales 
que guían el acuerdo en el marco de la ASEAN y los del ADPIC, sobre todo si se toma en cuenta que otros principios del mismo acuerdo disponen que los miembros de la asociación tienen que esforzarse por poner en operación arreglos de cooperación en la materia que sean benéficos para los creadores, los productores y los usuarios de la propiedad intelectual, de manera que conduzcan al bienestar social y económico, además de que se reconozca la protección y reforzamiento de los derechos de propiedad intelectual en cada estado miembro y la adopción de medidas necesarias para la protección de la salud pública y la promoción del interés público en sectores de importancia vital para el desarrollo económico, social y tecnológico.

Finalmente, el acuerdo también establece que los miembros deben estar conscientes y entender la necesidad de que cada estado adopte las medidas necesarias para prevenir el abuso por parte de los propietarios de los derechos, así como evitar que éstos recurran a prácticas que irrazonablemente restrinjan el comercio o afecten de manera adversa la transferencia internacional de tecnología, ${ }^{8}$ en detrimento de lo intereses legítimos de los miembros de la ASEAN.

Tanto en los objetivos como en los principios del acuerdo, independientemente de los compromisos adquiridos en otros convenios o con diferentes organismos, no hay una disposición contundente que indique la fortaleza de las medidas. Sin embargo, el artículo 6 del acuerdo establece que "nada en este acuerdo deberá perjudicar ningún acuerdo futuro, ya sea bilateral o multilateral, al que entre cualquier estado miembro o a las leyes nacionales de cada uno de ellos en relación con la protección y reforzamiento de los derechos de propiedad intelectual". ${ }^{9}$ Esto indica que el funcionamiento del régimen internacional de propiedad intelectual, representado por el ADPIC, en el marco de la ASEAN es bastante débil, pues las leyes nacionales en la materia están por encima de éste.
Además, la instancia que promovería su aplicación, desde este organismo, parece que ha dejado de existir o, si acaso existiera, no opera de acuerdo con lo que se pudiera esperar. En efecto, el Grupo de Trabajo sobre Cooperación en Propiedad Intelectual en la ASEAN (creado en junio de 1994), después de haber diseñado el acuerdo y el programa de acción 1996-1998, no ha tenido, o reportado al menos, ninguna otra actividad sobresaliente. Así, las actividades contempladas en el mencionado plan de acción no se han llevado a cabo.

Entre las actividades propuestas figuran las de establecer un grupo de expertos, al estilo del de APEC, que funcionaría también como una comunidad epistémica ${ }^{10}$ en la ASEAN, para inculcar información sobre la administración, registro y las infracciones sobre la propiedad intelectual en la ASEAN; organizar seminarios y reuniones para facilitar la interacción entre los participantes en el tema; facilitar el intercambio de información sobre los procedimientos, prácticas y administración entre las oficinas de propiedad intelectual de los miembros de la ASEAN; promover la participación del sector privado en la formulación de guías para la promoción de la creatividad; considerar la posibilidad de establecer mecanismos de manejo de disputas alternativos y fomentar una cooperación más estrecha entre las asociaciones de propiedad intelectual de los países de la ASEAN. ${ }^{11}$

De este modo, si el acuerdo no propone firmemente la aplicación del ADPIC en los países miembros de la asociación y ni siquiera promueve que se difundan más ampliamente las ventajas del mejoramiento de los niveles de protección de los derechos de propiedad intelectual, el reforzamiento que se pudiera esperar como resultado de la operación del régimen internacional no se observará.

Tampoco se identifica al interior de la ASEAN un poder hegemónico que pudiera ejercer alguna presión para forzar la aplicación de las disposiciones del ADPIC, suponiendo que dicho poder sea suficiente para propiciar el aca- 
tamiento del régimen internacional existente. ${ }^{12}$ Así, el mencionado régimen no ha estado en operación de manera inequívoca en la ASEAN.

Sin embargo, aunque sea de una manera débil, el régimen de propiedad intelectual ha estado avanzando y se ha ido fortaleciendo, aun cuando parece que no hay las precondiciones para que esto suceda, es decir, un poder hegemónico que por medio de la coerción posibilite el avance en el nivel de protección existente en cada uno de los estados miembros, ni una comunidad epistémica que por medio de la difusión de ideas y conocimientos nuevos promueva la protección efectiva y adecuada de los derechos de propiedad intelectual en la región.

De acuerdo con lo anterior, se puede argumentar que el régimen de protección de derechos de propiedad intelectual en la ASEAN ha tomado su propia dinámica; es decir, ha experimentado un proceso de retroalimentación ${ }^{13}$ específico, en virtud de que los actores responden de manera diferente a las mismas condicionantes externas. Esto es, el funcionamiento del mencionado régimen ha avanzado a su propio ritmo, aunque no con la misma fortaleza y velocidad que se ha conseguido en la materia a nivel global.

Esto es evidente también en las diferencias que muestra con respecto al comportamiento del régimen internacional representado por el ADPIC, puesto que en la ASEAN "los principios, normas, reglas y procedimientos de toma de decisiones tienen su propio impacto exógeno sobre los resultados y la conducta" ${ }^{14}$ de los actores regionales.

El rezago del régimen de propiedad intelectual en la ASEAN es notorio en el sentido de que la relación entre las variables causales básicas que dieron origen al régimen tienden a atenuarse, por lo que el régimen en cuestión tiene un impacto independiente sobre los resultados y la conducta de los actores regionales relacionada con este tema.

\section{Conclusiones}

En la ASEAN el régimen internacional de protección de derechos de propiedad intelectual ha adquirido su propio funcionamiento, independientemente de la evolución y fortaleza -o debilidad en todo caso- del régimen global representado por el ADPIC. Sin embargo, en la asociación no se estipulan medidas más fuertes que las dispuestas en el ADPIC, por lo que cuando mucho tendría su misma fortaleza. Pero dado el establecimiento de ciertos principios en materia de propiedad intelectual asentados en el Acuerdo Marco para la Cooperación sobre Propiedad Intelectual en la ASEAN (los cuales pudieran entrar en conflicto con los del ADPIC), se nota una cierta debilidad en el funcionamiento del régimen en el contexto de la ASEAN.

Gracias a que se reconoce la importancia de los derechos de propiedad intelectual en la conducción del comercio y los flujos de inversión, el acuerdo recomienda la cooperación estrecha entre los miembros de la ASEAN, a fin de fortalecer la protección de tales derechos con miras al establecimiento de una base firme para el progreso económico de sus estados miembros.

El deficiente funcionamiento del régimen global de protección de derechos de propiedad intelectual en la ASEAN puede deberse, según lo vimos, a la carencia de elementos que promuevan una mayor atención sobre el tema. En primera instancia pudiera pensarse en algunos países miembros, quizá los más avanzados en la región, que influyeran para que dicha atención sobre la materia se hiciera más firme, posibilitando así un aumento en el nivel de protección efectiva de los derechos de propiedad intelectual.

Además, la falta de operación real del Grupo de Trabajo sobre Cooperación en Propiedad Intelectual de la ASEAN, no ha permitido una mayor difusión de las ideas y conocimientos nuevos que fortalezcan y refrenden la importancia de la protección adecuada y efectiva de los derechos de propiedad inte- 
lectual; tampoco ha fomentado el acercamiento entre los sectores público y privado, ya sea al interior de cada estado miembro o entre los países mismos, lo que tendría como consecuencia una mayor aceptación de las premisas fundamentales de la protección de la propiedad intelectual.

Así, aunque con una fortaleza menos pronunciada que en el nivel global, la protección de los derechos de propiedad intelectual en la ASEAN ha generado su propio ritmo y dinámica, aunque menor que la registrada en el ADPIC.

\section{Notas}

1 ASEAN Framework Agreement on Intellectual Property Cooperation, Bangkok, Tailandia, 15 de diciembre de 1995. Está disponible una versión electrónica de este acuerdo en http://www.aseansec.org/2687.htm.

2 Éste se entiende como los principios, normas, reglas y procedimientos de toma de decisiones alrededor de los cuales las expectativas de los actores convergen en un área de tema dada de relaciones internacionales. Para profundizar en el concepto, véanse: Stephen D. Krasner (ed.) International Regimes, Cornell University Press, Ithaca, 1983; y Andreas Hasenclever, Peter Mayer y Volker Rittberger, Theories of International Regimes, Cambridge University Press, Cambridge, Reino Unido, 2000 .
3 Vid Organización Mundial de la Propiedad Intelectual, "Acuerdo sobre los Aspectos de los Derechos de Propiedad Intelectual Relacionados con el Comercio (acuerdo sobre los ADPIC)", en Publicación OMPI núm. 223(S), Ginebra, 1996, pp. 13-65. También conocido como TRIPS, por sus siglas en inglés (Trade Related Aspects of Intellectual Property Rights). Una versión en inglés se puede consultar en http://www.wto.org/english/docs e/ legal e/27-trips.doc.

4 ASEAN Framework Agreement on Intellectual Property Cooperation, art. 2 (2).

5 Estos países son Camboya, Laos y Vietnam.

6 ASEAN Framework Agreement on Intellectual Property Cooperation, art. 1 (1-3).

7 Ibid., art. 1 (4-6).

8 Ibid., art. 2.

9 Idem.

10 Las comunidades epistémicas se definen como redes de profesionales con experiencia y competencia reconocida en un dominio particular y una opinión autorizada en el conocimiento relevante para las políticas dentro de ese dominio o área de tema.

11 Program of Action 1996-1998 on ASEAN Intellectual Property Cooperation, en http://www.aseansec.org/ economic/pa aipc.htm.

12 Cfr. Robert O. Keohane, After Hegemony: Cooperation and Discord in the World Political Economy, Princeton University Press, Princeton, 1984, p. 31.

13 Stephen D. Krasner, "Regimes and the Limits of Realism: Regimes as Autonomous Variables", en Stephen D. Krasner (ed.), op. cit., p. 361.

14 Ibid., p. 359.m:? 